\title{
The Ultrastructure of Capillaries and Arterioles of the Hamster Dental Pulp'
}

\author{
SEONG S. HAN AND JAMES K. AVERY \\ School of Dentistry, The University of Michigan, Ann Arbor, Michigan
}

\begin{abstract}
The ultrastructure of capillaries and arterioles of the hamster dental pulp has been studied. Pieces of the incisor pulp were fixed in $1 \% \mathrm{OsO}_{4}$ buffered with $0.14 \mathrm{M}$ veronal acetate, embedded in epoxy resin and studied in an electron microscope. The basic cytoplasmic organization of endothelial cells confirmed observations on blood vessels of other organs made by previous investigators. A large number of intracytoplasmic fibrils were found in many endothelial cells, and their presence was discussed in relation to earlier reports on the contractility of endothelial cells. Previous observations on the structural details of the intercellular region of the endothelium were confirmed and elaborated upon. The manner in which the cytoplasmic flaps of adjoining cells were oriented indicated that, if the integrity of the capillary wall was maintained, only cells with capacity for ameboid movement could creep through the region. Thus they were thought to play a role as an effective barrier against the passage of red blood cells. Numerous micropinocytosis and pinocytosis vesicles were found in association with plasma membranes. The significance of their structure in the transport of materials across the capillary wall is discussed. The fine structure of the pericyte resembled that of the fibroblast. Portions of plasma membranes of adjacent smooth muscle cells in the media of arterioles were brought together closely and resembled attachment zones.
\end{abstract}

The ultrastructure of blood capillaries and arteries has been studied by many authors in different organs (Donahue and Pappas, '61; Ekholm, '57; Farquhar, '61; Fawcett, '59; Gloor, '58; Kisch, '57; Moore and Ruska, '57; Palade, '53, '60 and '61; Rinehart and Farquhar, '55; and others), and an effort has been made to classify capillaries on the basis of their structure (Bennett, Luft and Hampton, '59). The basic structural characteristics that are common in most capillaries so far studied can be summarized as follows. The endothelium is composed of a layer of flat cells making contact with one another at their periphery where the cytoplasm becomes attenuated: An ovoid nucleus with occasionally wrinkled contour presents a central bulging in the cytoplasm. In the paranuclear cytoplasm are found a few short profiles of endoplasmic reticulum, small and usually round mitochondria, some free ribosomes, a small Golgi apparatus, and a large number of small vesicles which are frequently associated with the plasma membrane. In certain glands and renal glomeruli the attenuated periphery of the cytoplasm presents small pores that are traversed by a thin membranous structure which has been called a diaphragm
(Farquhar, '61 and Rhodin, '62). An uninterrupted basement membrane wraps around the endothelium, and often becomes continuous with the interstitial connective tissue fibers.

During the past several years leading students of capillary morphology (Fawcett, '59; Palade, '61; and Farquhar, Wissig and Palade, '61) have attempted to evaluate the intriguing theories of physiologists that the intercellular cement substances are important, and active transfer of matters by "phagocytosis" through the cytoplasm is unlikely to take place (Chambers and Zweifach, '47), and that the intercellular region may be of porous structure akin to a sieve for the transport of water and water-soluble substances, and only oxygen and other lipid-soluble substances pass through the cytoplasm (Pappenheimer, Renkin and Borrero, '51). Contrary to the concept of Chambers and Zweifach that the fluid transfer may not be achieved by cytoplasmic activities, however, works of Palade ('61) and Farquhar et al. ('61) strongly suggest that the micropinocytosis vesicles may play an important role, along with the basement

1 This investigation was supported by U.S.P.H.S. research grant D-1620 from the National Institute of
Dental Research, National Institutes of Health. 
membrane, in the transport of fluid and particulate matters as evidenced by transfer of ferritin and other colloidal particles through glomerular capillaries. Recently Fawcett and Wittenberg ('62) have pointed out that the cytoplasmic flaps in the intercellular region of the choroid rete in the fish eye might be involved in the formation of large pinocytosis vacuoles. Thus, in as much as the correlation of physiological concepts with morphology is concerned, the advancement in knowledge of the structure has so far failed to produce a unified idea on the manner by which transport of matters across the capillary takes place.

The contractility of capillaries has been observed and attributed to the action of pericytes by Rouget (1873 and 1879), while Clark and Clark ('25) and Federighi ('27) described the contraction of endothelial cells without pericytes. Although the claim that intracellular fibrils exist in endothelial cells has been made by both light microscopists (Rio Hortega, '17) and electron microscopists (Palade, ' 53 , and Fawcett, ' 59 ), there is a lack of evidence illustrating their anatomical identity. Also, the structural relationship of smooth muscle cells to each other has been described in different ways (Bergman, '56; Thaemert, '59; and Dewey and Barr, '62).

In 1871 the pericyte first was described as "adventitia capillaris" or "Gesfaessperithel" by Eberth. Zimmermann ('23) was the first to call it the pericyte. With respect to the nature of the cell the literature shows a great deal of controversial thoughts among early histologists. Rouget (1873) described the possible contractility of the cell and many workers, including Steinach and Kahn ('03), Vimtrup ('23) and Krogh in 1924 ('59) agreed with the theory. Bensley and Vimtrup (28) claimed that by staining with Janus Green B they were able to visualize the finest fibrils on the capillary wall and called them myofibrils of the pericyte. Zimmermann ('23) advanced the view that the cell was concerned with the regulation of fluid passage through the capillary wall. These views have been challenged by other authors. According to Benninghoff (' 30 ) that the cell was fibrocyte in nature was first suggested in 1872 by Ranvier who observed a gradual transition of smooth muscle cells to fibrocytes in the end of arterioles, and that capillaries were covered by fibrocytes. Ohno ('24) claimed that the cell had no contractility, and Clark and Clark ('25) observed a separation of the capillary wall and pericyte upon constriction of the former. Benninghoff ('26) stated that the pericyte cytoplasm in mammals was similar to that of the fibroblast, lacking myofibrils, and reticular fibers being found in association with the cell surface. He also noted that under certain stimulations the pericyte would proliferate by thickening of the cytoplasm and by mitosis, and show histiocytic characteristics of ingesting vital dyes. Although Fawcett ('59) noted that the structure of the pericyte could not be distinguished from that of the endothelial cell, the ultrastructure of the cell has not been clarified to any appreciable extent.

The present communication aims to describe and discuss the fine structure of capillaries and aterioles in the dental pulp, emphasizing the appearance of intracytoplasmic fibrils within endothelial cells, the structure of the intercellular region of the endothelium, the ultrastructure of the pericyte, and the arrangement of smooth muscle cells in the media of arterioles.

\section{MATERIALS AND METHODS}

Twelve female Syrian hamsters, two months of age, were used in the study. Under ether anesthesia the mandibles were rapidly resected and bisected at the median suture. To expose the incisor the base of the mandible was carefully chipped off until the tooth became free. By cracking the soft part of root dentin and pulling the pulp by the proximal end, the entire pulp tissue was removed from the tooth without visible damage. It then was immediately immersed in a solution of $2 \%$ buffered osmium tetroxide buffered at $\mathrm{pH}$ 7.4 with $0.14 \mathrm{M}$ veronal acetate containing $4.5 \%$ sucrose. After a few minutes the tissue was sliced into small pieces which were fixed for a period of two to four hours. Following dehydration in ethanol the tissues were embedded in a mixture of epoxy resin according to Luft's method ('61). Thin sections were made on a Porter-Blum microtome, picked up on 
formvar coated grids which were reinforced with a thin layer of carbon and stained for 30 minutes in $0.1 \%$ phosphotungstic acid followed by one hour in a saturated uranyl acetate solution. Photomicrographs were taken in a Hitachi HU-11 electron microscope.

\section{OBSERVATIONS}

Endothelial cells. The submicroscopic organization of endothelial cells generally confirmed the results of previous studies summarized in the introduction. The cell was flat and had an oval nucleus. The nuclear membrane often appeared wrinkled (fig. 1). The peripheral cytoplasm was attenuated for varying distances, and contacted the cytoplasmic ends of adjoining cells. In small arteries the cell often assumed a polygonal to round shape (fig. 4). Intracytoplasmic structures included a number of elements of rough endoplasmic reticulum with short and flat saccular profiles, a few to several small and usually round mitochondria, clusters of ribosomes, small Golgi apparatus with centrioles, occasional dense granules and numerous micropinocytosis vesicles ${ }^{2}$ (figs. 1, 4 and 5).

The micropinocytosis vesicles measured 60 to $70 \mathrm{~m} \mu$ in diameter, and were located most abundantly along the luminal and basal plasma membranes (figs. 1, 4 and 6). Many of them appeared to have established a continuity with the plasma membrane, emptying their contents into the vascular lumen or tissue space (figs. 4 and 5 ). With equal validity the relationship could be interpreted as inpocketings of the plasma membrane pinched off to form vesicles which may be subsequently transported to other regions in the cytoplasm. Occasionally the vesicles seemed to line up and coalesce to form a channel or an irregularly shaped sac of different sizes (figs. 5 and 21 ).

Along attenuated portions of peripheral cytoplasm where thickness was less than $100 \mathrm{~m} \mu$, pores of approximately 50 to $70 \mathrm{~m} \mu$ in diameter were observed (fig. 9). Where the cytoplasm was thicker the pores were incomplete and appeared identical to inpocketings associated with micropinocytosis vesicles (fig. 8). In fact, in areas where the cytoplasm was even thicker, the inpocketing from one side seemed to unite with what appeared to be vesicles emptying into the other side of the cell (fig. 10). In addition, plasma membranes of the luminal side had occasional flap-like projections and invaginations which, upon contact with opposing membranes, appeared to form vacuoles that were much larger than micropinocytosis vesicles (figs. $1,7,11$ and 23).

A varying number of intracellular fibrils were present in many endothelial cells (figs. 5 and 6 ). The diameter of the fibrils was about 6 to $7 \mathrm{~m} \mu$. In favorably sectioned materials they presented long profiles which at certain points appeared to ramify or converge (fig. 6). Frequently they were present in bundles. When such bundles were formed, other cytoplasmic structures, e.g. the rough endoplasmic reticulum, clusters of ribosomes and mitochondria, were displaced by them (fig. 6). At times they were seen to be in contact with the plasma membrane at points of intercellular junction (fig. 3 ).

The endothelium had a continuous basement membrane which exhibited a varying thickness of $30 \mathrm{m \mu}$ or more, and was separated from the basal plasma membrane by a clear zone of approximately $15 \mathrm{~m} \mu$, the "subendothelial space" (Palade, '61) (fig. 1). The clear zone was continuous with the intercellular region. The outer border of the basement membrane was not regular (figs. 1 and 23), and its irregularity accounted for the variation in thickness of the basement membrane. Frequent association of collagen fibrils with the basement membrane at its outer border was observed.

Intercellular regions of the endothelium. The basic morphology of points of contact between adjacent endothelial cells was similar to previous observations made in blood vessels of other organs; the cytoplasmic ends of neighboring cells made a simple contact (figs. 2, 12 and 13), overlapping or an interdigitation (figs. 16 to 20 and 22). However, luminal tips of cytoplasmic ends showed interesting variations. When fairly thick ends made a simple contact the luminal tips protruded as small ridges or projections (figs. 12,

2 The term micropinocytosis vesicle is used in this article to designate intracytoplasmic vesicles of $65 \mathrm{~m} \mu$ in average diameter present in endothelial cells. 
13 and 15). One of such bulgings often extended itself out into the lumen to form a flap which appeared to bend over to the other side, covering the cytoplasmic end of the neighboring cell. In small capillaries where an erythrocyte could barely make its way through, such flaps always gave the appearance that they were forced to fold over to the other side, as if they were preventing the red blood cell from penetrating into the intercellular region (figs. 13,15 and 20). Frequently a third piece of cytoplasm made an additional flap from another direction (figs. 14 and 18). A number of inpocketings and invaginations of the luminal plasma membrane were found in association with these flaps, forming vacuoles of irregular size and shape (fig. 21). More often large invaginations were observed at the base of the flap. The shape of such invaginations frequently indicated that they might be closed off at their neck to form a vacuole by the folding back of the flap, or by a secondary bulging of the plasma membrane (figs. 11 and 15).

A uniform lucent zone of 10 to $12 \mathrm{m \mu}$ separated the surfaces of adjoining cells (figs. 16, 17 and 22). This zone was continuous with the lumen on one side and the clear zone between the endothelium and basement membrane on the other. Sometimes inpocketings of the plasma membrane along the intercellular space were observed (figs. 2, 19 and 22). Associated with them were occasional dilatations of the space (fig. 19) which also occurred without the presence of inpocketings (fig. 22). The "adhesion plate" (Bennett et al., '59) or attachment zone was observed in the pulp vessels, too. It was identified by the characteristic densification of intercellular materials, apposing membranes and cytoplasmic matrix of the region (figs. 17, 19 and 22). An additional point of interest was that some of the intracytoplasmic fibrils made contact with the attachment zone (fig. 3). No dilatations of intercellular space as described above were present in this zone.

Pericytes. In most section of capillaries, portions of cytoplasm of the pericyte were present (figs. 1, 16, 23 and 24). When a section was made through the cell body the following features were ob- served. The cell was spindle-shaped, and was bent following the outline of the vessel. Although a degree of variation existed in the cytoplasmic organization of the cell, the general structure of the cytoplasm was characterized by a well developed paranuclear Golgi complex and rough endoplasmic reticulum among other organelles (figs. 1 and 24). The Golgi complex was composed of short bilaminar membranes with blind ends, numerous vesicles and small vacuoles and occasional dense bodies. They were bordered by a limiting membrane (fig. 24) and were similar to dense granules found in fiber-associated reticular cells (Han, '61). Short profiles of the rough endoplasmic reticulum were distributed throughout cytoplasm in varying numbers. The cisternae were more or less flat and contained materials of moderate electron density. Of those located near Golgi components some endoplasmic reticulum was partially devoid of studded ribosomes (fig. 24). Such smooth portions often appeared to have a continuity with vesicles and membranes of the Golgi complex. Mitochondria were round and small with only a few cristae. They were scattered in various parts of the cytoplasm. Micropinocytosis vesicles were seldom found within pericytes. The ground cytoplasm was moderately dense. Often a dense, irregular structure which simulated the appearance of a basement membrane was found covering portions of the cell surface (figs. 16 and 24). Sometimes the layer on the capillary side merged with the basement membrane of the vessel and could not be distinguished from it. A number of collagen fibrils were located close to the surface, singly or in groups (fig. 1).

Arterioles. Except for the somewhat cuboid shape of the endothelial cell, the cytoplasm of cells of the endothelium of small arteries was not different from that of capillaries. However, the arrangement of the media was of interest. In the cytoplasm of smooth muscle cells were numerous myofilaments which tended to displace the Golgi apparatus, the rough endoplasmic reticulum and small mitochondria in certain areas (fig. 25), although mitochondria were found between the myofibrils also. Cross-sectioned myo- 
fibrils showed sporadic dense areas which, when longitudinally sectioned, appeared as typical "fusiform densities" (fig. 26). Many inpocketings and vesicles were present along the surface membrane which was covered by a layer of dense material approximately $30 \mathrm{~m} \mu$ in thickness and was separated by fibrous elements from the neighboring cell. At certain points parts of plasma membranes of adjacent cells were brought into a close proximity, separated only by a lucent zone 25 to $30 \mathrm{m \mu}$ wide.

This region occasionally exhibited areas where the opposing membranes and underlying cytoplasm showed an increase in density, and thus resembled an attachment zone (arrows, fig. 25). Many collagen fibrils were found between muscle cells, often forming bundles of varying sizes. Homogeneous, irregular and fairly dense areas similar to elastic fibers described by others were present in close relation with collagen fibrils (fig. 26). Also, fine fibrils of $10 \mathrm{m \mu}$ or less in diameter were found in the area. At the external surface of the smooth muscle layer these fibrous elements became continuous with those in the adjacent connective tissue.

\section{DISCUSSION}

Intracytoplasmic fibrils and contractility of the endothelial cells. As mentioned in the introduction, Rouget (1873 and 1879) described capillary contraction which he believed to be a function of pericytes. Later Clark and Clark ('25) reported that contraction took place in the absence of the pericyte. More recently the presence of intracellular fibrils $24 \mathrm{~m} \mu$ in diameter was described by Palade ('53), and has been confirmed by Fawcett ('59) who pointed out that the diameter of the fibrils was less than $10 \mathrm{~m} \mu$ instead of being 24 $\mathrm{m} \mu$. Fawcett further described that the tracts of oriented filaments were consistent with the belief that the endothelial cells might have a considerable contractility of their own. Our observations confirm those of Fawcett and clearly demonstrate the presence of fibril tracts within the cytoplasm. That other cytoplasmic structures appeared to be displaced by the tracts might be taken as an indication of their physically preferential orientation. As- suming that they are contractile elements such an arrangement would be a reasonable one, as in the case of muscle cells. In addition, the merging of the fibrils toward the attachment zone suggests that the latter would be an ideal point of anchorage for the fibrils, if the cells are to contract in relation to one another. However, mention should be made of the possibility that, since the attachment zone is thought to be comparable to a desmosome, the fibrils attached to the zone might be analogous in nature to tonofibrils of the epithelium. Furthermore, many cells such as leucocytes, macrophages, tumor cells and certain cultured cells have been shown to contain various intracellular fibrils. This fact might mean that the fibrils, including some of those in the endothelium, could serve as a sort of cytoskeleton.

Pinocytosis and micropinocytosis. The phenomenon of pinocytosis in the capillaries may be of two kinds. The vesicles of uniform size ( 60 to $70 \mathrm{m \mu}$ in diameter), micropinocytosis vesicles, appear to originate from the luminal and/or basal plasma membranes by the pinching off of small inpocketings, and would correspond to those vesicles that transport colloidal particles across the capillary endothelium (Palade, '60; and Farquhar et al., '61). On the other hand, the appearance of large invaginations and vacuoles, pinocytosis vacuoles, observed particularly in the vicinity of the intercellular region along the luminal plasma membrane surface might reflect their dependence on the activity of the surface membrane. This agrees with the idea of Fawcett and Wittenberg ('62) that large pinocytosis vacuoles are formed by the fusion of luminal cytoplasmic flanges at intercellular junctions. It is also possible that large vacuoles could be formed by coalescing micropinocytosis vesicles which, depending on the number of vesicles concerned, would produce vacuoles of varying size (fig. 21).

Apparently no cytoplasmic fenestrations comparable to those described in capillaries of glomeruli (Rhodin, '62) and endocrine organs (Farquhar, '61) are present in capillaries of the dental pulp. Although occasional pores were seen at extremely attenuated portions of cytoplasm, establishing a continuity between the capillary 
lumen and "subendothelial space," no diaphragm or knot (Rhodin, '62) was observed. Instead, a number of photographs (figs. 8 and 9) suggested that these were indeed the result of micropinocytosis which, owing to the thinness of cytoplasm, established transitory pores or channels. Coalescing small vesicles and inpocketings as shown in figure 10 indicate further that such channels could be established also in areas where the cytoplasm is relatively thick.

Thus, observations made in this report as well as those from previous studies appear to support the original proposal of Palade ('53) that pinocytotic activities of the plasma membrane may be important in the transfer of fluid across the vessel. Whether or not a theoretical compromise between these findings and physiological concepts mentioned earlier is possible remains to be seen.

The possible role of cytoplasmic flaps in the movement of cells. With respect to additional significance in the functioning of cytoplasmic flaps located at the intercellular regions, our observations suggest the intriguing possibility that the flaps may act as a regulator for the passage of cellular elements through the capillary wall. Without exception the flap from one cell folded over and covered the cytoplasmic end of the other cell. Supposing that a red blood cell is imposing a pressure on the region as indicated in figure 13 , the folds would give no chance for the erythrocyte to pass through the region unless a nonphysiological rupture of the junction occurs. Therefore, it is likely that in order for a cell to pass through intercellular junctions of the capillary endothelium, one of the two following conditions must prevail. First, a cell having pseudopodia with potentials of ameboid movement could creep through the gap by inserting pseudopodia into it and temporarily opening the junction. The movement of certain leucocytes through the capillary wall might be achieved in this manner. As for erythrocytes, this would not be possible since they do not have the capacity for ameboid movement. Second, the junction might be opened by abnormal challenges, facilitating the passage of both red and white blood cells as well as other substances present in the plasma. The findings of Mazno and Palade ('61) suggest strongly that this is true. In their study of the effect of serotonin and histamine on the vascular permeability in the rat cremaster muscle, the separation of intercellular junctions of the endothelium was observed, and, as shown by subsequent intravenous injection of colloidal $\mathrm{HgS}$ as an electron marker, constituents of plasma as well as red cells were seen to leak out through the gap.

The intercellular attachment and cement substance. The uniformity of the width of the clear intercellular zone along endothelial junctions suggest the possibility that a "cement substance" which is either not preserved or electron-lucent might exist. Ohta et al, ('62) have reported the presence of a heparin-like substance which is not affected by $\mathrm{pH}$ (within a range of $\mathrm{pH} 2.4$ to 7.0 ) nor by hyaluronidase treatment, as judged from toluidine blue staining. Whether this substance is diffuse throughout the relatively lucent space or is piled up in a particular region is not known. Dilatations of the junction indicate that it is not rigid in all areas, and that a large stream of plasma could pass through the junction at certain areas. On the other hand, since neither dilatations nor invaginations are found at the dense attachment zone, a true mechanical anchorage between adjacent cells might be provided by the zone. Furthermore, the insertion of intracytoplasmic fibrils to the attachment zone resembles similar situations observed in the desmosome. Additional support for the mechanical rigidity of the attachment zone may be translated from Mazno and Palade's experiment ('61) in which the attachment zone was observed to be intact while gaps developed in intercellular space as the result of hista. mine or serotonin administration. The continuity of the clear zone of the intercellular junction to the "subendothelial space" is of interest for future study. Whether materials in both regions are of the same nature or whether the subendothelial space is a mere artefact of preparatory procedures is not understood, and calls for further knowledge of the chemistry of constituent materials.

The pericyte. Through studies on secretory cells it has been established that a 
prominent Golgi apparatus and abundant endoplasmic reticulum with associated ribosomes constitute the essential morphologic features of most cells which synthesize and secrete proteins. The ultrastructural characteristics of the pericyte described herein are in close accordance with the features mentioned above, and are similar to those of the fibroblast. In addition, the initimate positional relationship of collagen fibrils with the cell surface strongly suggests that the cell might produce the fibrils and deposit them on its surface. Such a relationship has been found to exist in fibroblasts (Porter and Pappas, '59).

On these grounds it is suggested that the primary function of the pericyte might be that of elaborating connective tissue of the pericapillary region in the same manner as a fibroblast does elsewhere in the body. This theory supports the classical concept of Ohno ('24), Benninghoff ('26) and others that the cell is a pericapillary fibroblast. Structural variations of individual cells observed in this study may indicate differences of functional status as well as the degree of maturity.

Intercellular connections between smooth muscle cells. In view of the general belief that a synchronous excitement of smooth muscle cells does exist, the structural relationship between smooth muscle cells has received considerable attention. That relationship has been described in three different ways. Firstly, it was described as an "intercellular bridge" by Bergman ('56) who observed initimate attachment zones between adjacent cell membranes in the ureteral smooth muscle. Fawcett ('59) recognized the same relationship in the smooth muscle of arterioles, and postulated that it might be significant in the spread of the contractile process during constriction of the vessels. However, Fawcett declined to call the zone an "intercellular bridge" on the basis of the lack of specialization in apposed membranes. Secondly, a distinct cytoplasmic continuity between smooth muscle cells was found by Mark ('56) in the uterus and by Thaemert ('59) in the stomach. The latter named it an "anastomosing intercellular bridge." And thirdly, Dewey and Barr ('62) have described a fusion of the outer layers of apposing plasma membranes observed in the jejunal smooth muscle cells of the dog. A new word, "nexus," was proposed to express the relationship. In order to determine whether or not all three types of attachment do exist in the same organ or are due to differences in the techniques and organs studied, further investigations are necessary. In this particular study only the situation similar to the first type has been demonstrated.

\section{LITERATURE CITED}

Bennett, H. S., J. H. Luft and J. C. Hampton 1959 Morphological classification of vertebrate blood capillaries. Am. J. Physiol, 196: 381-390.

Benninghoff, A. 1926 Ueber die Formenreihe der glatten Muskulatur und die Bedeutung der Rougetschen Zellen an den Capillaren. Z. Zellforsch, u. micro. Anat, 4: 125-170. 1930 Die Capillaren. In Handbuch der mikroskopischen Anatomie des Menschen. Julius Springer, Berlin, pp. 18-49.

Bensley, R. R., and B. Vimtrup 1928 On the nature of the Rouget cells of capillaries. Anat. Rec., 39: 37-55.

Bergman, R. A. 1956 Intercellular bridges in ureteral smooth muscle. Johns Hopkins Hosp. Bull., 102: 195-202.

Chambers, R., and B. W. Zweifach 1947 Intercellular cement and capillary permeability. Physiol. Rev., 27: 431-463 (Review).

Clark, E. R., and E. L. Clark 1925 A. On the development of adventitial (Rouget) cells on the blood capillaries of amphibian larvae. B. The relation of "Rouget" cells to capillary contractility. Am. J. Anat., 35: 239-282.

Donahue, S., and G. D. Pappas 1961 The fine structure of capillaries in the cerebral cortex of the rat at various stages of development. Ibid., 108: 331-40.

Dewey, M. M., and L. Barr 1962 Intercellular connection between smooth muscle cells: the nexus. Science, 137: 670-672.

Ekholm, R. 1957 The ultrastructure of the blood capillaries in the mouse thyroid gland. Ztschr. Zellforsch. u. mikroskop. Anat., 46: 139-146.

Farquhar, M. G. 1961 Fine structure and function in capillaries of the anterior pituitary gland. Angiology, 12: 270-292.

Farquhar, M. G., S. L. Wissig and G. E. Palade 1961 Glomerular permeability. I. Ferritin transfer across the normal glomerular capillary wall. J. Exp. Med., 113: 47-66.

Fawcett, D. W. 1959 The fine structure of capillaries, arterioles and small arteries. In Microcirculation. S. R. M. Reynolds and $B$. Zweifach, ed., Univ, Ill. Press, Urbana, pp. 127.

Fawcett, D. W., and J. Wittenberg 1962 Structural specializations of endothelial cell junctions. Anat. Rec., 142: 231 (abstract). 
Federighi, H. 1927 Blood vessels of annelids. Proc. Nat. Acad. Sc., 13: 639-641.

Gloor, F. 1958 Ueber die Ultrastruktur der Pankreaskapillaren. Acta Anat., 35: 63-84.

Han, S. S. 1961 The ultrastructure of the mesenteric lymph node of the rat. Am. J. Anat., 109: 183-226.

Kisch, B. 1957 Der ultramicroscopische Bau der Capillarwand. Acta physiol. pharma. neerl., 6: 334-38.

Krogh, A. 1959 The Anatomy and Physiology of Capillaries. Yale U. Press, New Haven.

Luft, J. J. 1961 Improvements in epoxy resin embedding methods. J. Biophys. Biochem. Cytol., 9: 409-414.

Mark, J. S. T. 1956 An electron microscope study of uterine smooth muscle. Anat. Rec., 125: $473-493$.

Mazno, G., and G. E. Palade 1961 Studies on inflammation. I. The effect of histamine and serotonin on vascular permeability: an electron microscopic study. J. Biophys. Biochem. Cytol., 11: 571-605.

Moore, D. H., and H. Ruska 1957 The fine structure of capillaries and small arteries. J. Biophys. Biochem. Cytol., 3: 457-461.

Ohno, F. 1924 Beitrage zur Frage der neurophysiologischen Entzundungslehre. Beitr. path. Anat., 72: 722-759.

Ohta, G., H. Sasaki, F. Matsubara, F. Tanishima and S. Watanabe 1962 Heparin-like substances in cement lines of vascular endothelium of guinea pigs. Proc. Soc. Exp. Biol. Med., 109: 298-300.

Palade, G. E. 1953 Fine structure of blood capillaries. J. Appl. Phys., 24: 1424 (abstract).

Palade, G. E. 1960 Transport in quanta across the endothelium of blood capillaries. Anat. Rec., 136: 254 (abstract).

1961 Blood capillaries of the heart and other organs. Circ., 24: 368-384.
Pappenheimer, J. R., E. M. Rankin and L. M. Borrero 1951 Filtration, diffusion and molecular sieving through peripheral capillary membranes. A contribution to the pore theory of capillary permeability. Am. J. Physiol, 167: 13-51.

Porter, K. R., and G. D. Pappas 1959 Collagen formation by fibroblasts of the chick embryo dermis. J. Biophys. Biochem. Cytol., 5: 153166.

Rhodin, J. A. D. 1962 The diaphragm of capillary endothelial fenestrations. J. Ultrastructure Res., 6: 171-185.

Rinehart, J. F., and M. G. Farquhar 1955 The fine vascular organization of the anterior pituitary gland. An electron microscopic study with histochemical correlations. Anat. Rec., 121: $207-240$.

Rio Hortega, P. del 1917 Contribution al conocimiento de las epitelio-fibrillas. Trab. Labor. Invest. Biol., Univ. Madrid, 15: 201-299.

Rouget, C. 1873 Memoire sur les capillaires sanguins et lymphatiques. Arch. Physiol., 6-31 (cit. by Benninghoff,' 30 ).

- 1879 Sur la contractilite des capillaires sanguins. C. r. Soc. Biol., 88: 916 (cit. by Benninghoff, '30).

Steinach, E., and R. H. Kahn 1903 Echte Contractilitaet und motorische Innervation der Blutcapillaren. Pfluegers Arch. Physiol., 9: $105-133$.

Thaemert, J. C. 1959 Intercellular bridges as protoplasmic anastomoses between smooth muscle cells. J. Biophys. Biochem. Cytol., 6: 6770.

Vimtrup, B. 1923 Beitrage zur Anatomie der capillaren. II. Weitere Untersuchungen ueber contractile Elemente in der Blutgafaesswand der Blutcapillaren. Z. Anat., 68: 469-82.

Zimmermann, K. W. 1923 Der feinere Bau der Blutcapillaren. Z. Anat., 68: 29.

1 A transversely sectioned capillary from the hamster incisor pulp, showing the endothelium, basement membrane and pericyte (p). The endothelial cell has numerous micropinocytosis vesicles ( $v$ ) and a nucleus with wrinkled contour. Notice the collagen fibrils (arrows) seen along the surface of the pericyte. $\times 15,200$.

2 A simple contact made by relatively thick cytoplasmic ends of adjoining endothelial cells. Several micropinocytosis vesicles and inpocketings are seen along the apposing plasma membranes. $\times 24,000$.

3 An atachment zone which is sectioned obliquely. A large number of intracytoplasmic fibers appear to converge into the zone. $\times 38,000$. 


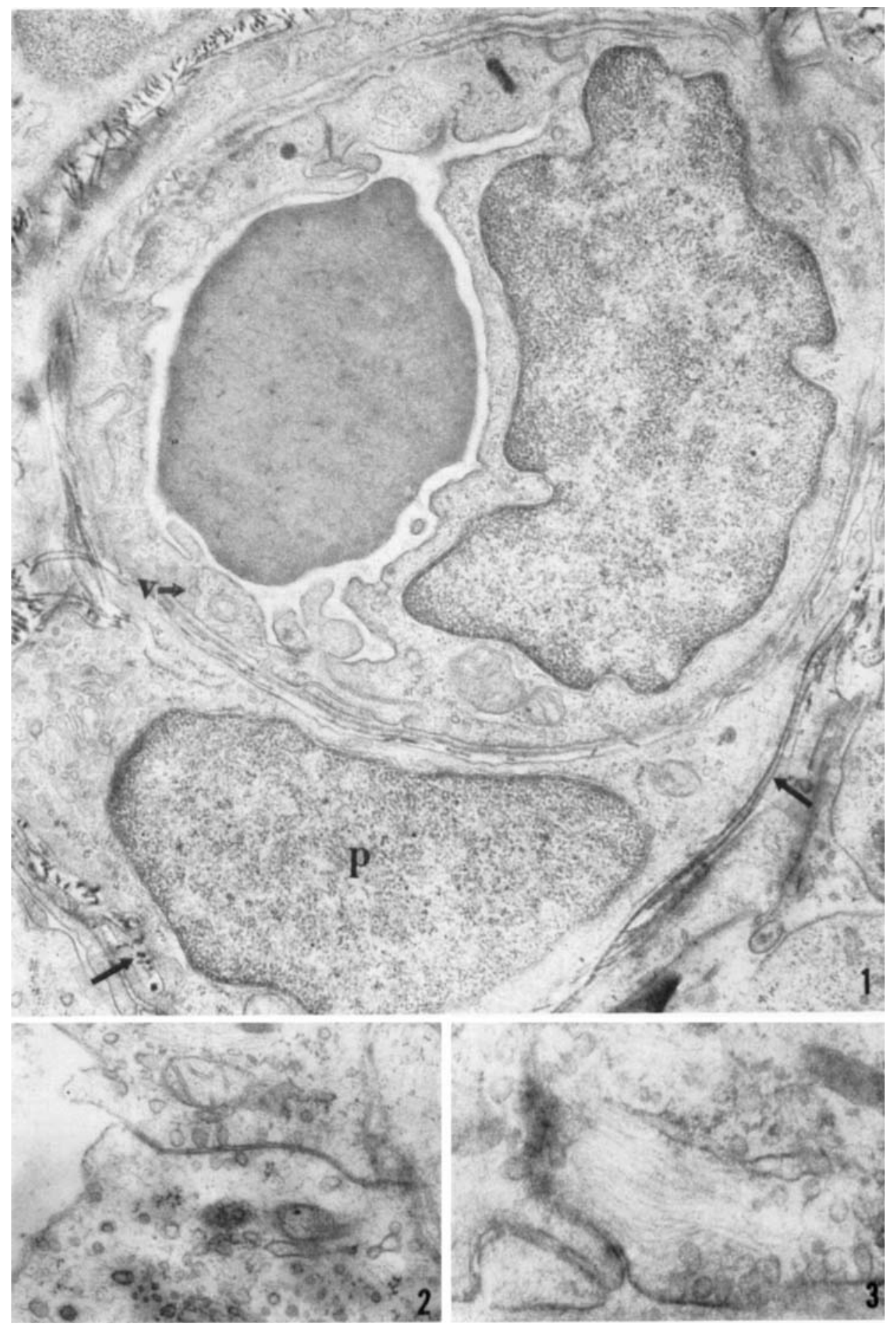


PLATE 2

EXPLANATION OF FIGURE

4 An endothelial cell from an arteriole. The shape of the cell is more or less cuboid. Intracytoplasmic structures include endoplasmic reticulum (er), ribosomes, mitochondria $(\mathrm{m})$ and vesicles. Irregularities of the surface plasma membrane at the intercellular junction (long arrows) and along the luminal surface (short arrows) may be seen. $\times 18,000$. 


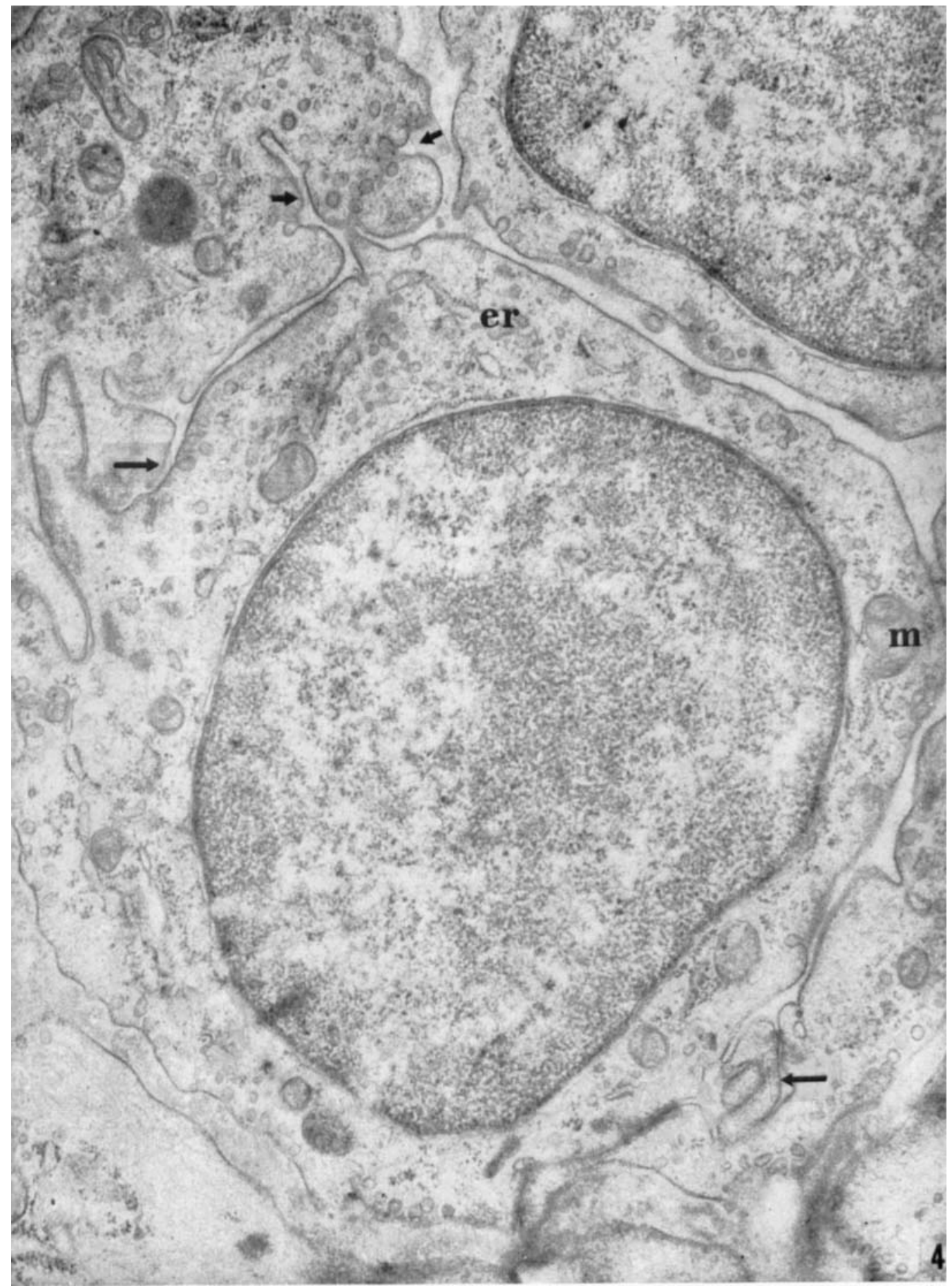


PLATE 3

EXPLANATION OF FIGURES

5 Portions of cytoplasm of endothelial cells. Numerous micropinocytosis vesicles and inpocketings along the luminal plasma membrane appear to coalesce (arrow). The cytoplasm of the upper cell shows some fibrils within it $(f) . \times 18,000$.

6 A portion of cytoplasm of the endothelial cell. Numerous fine intracytoplasmic fibrils are running in parallel forming a tract ( $t)$. Clusters of ribosomes appear to be displaced by the tract. $\times 76,800$. 

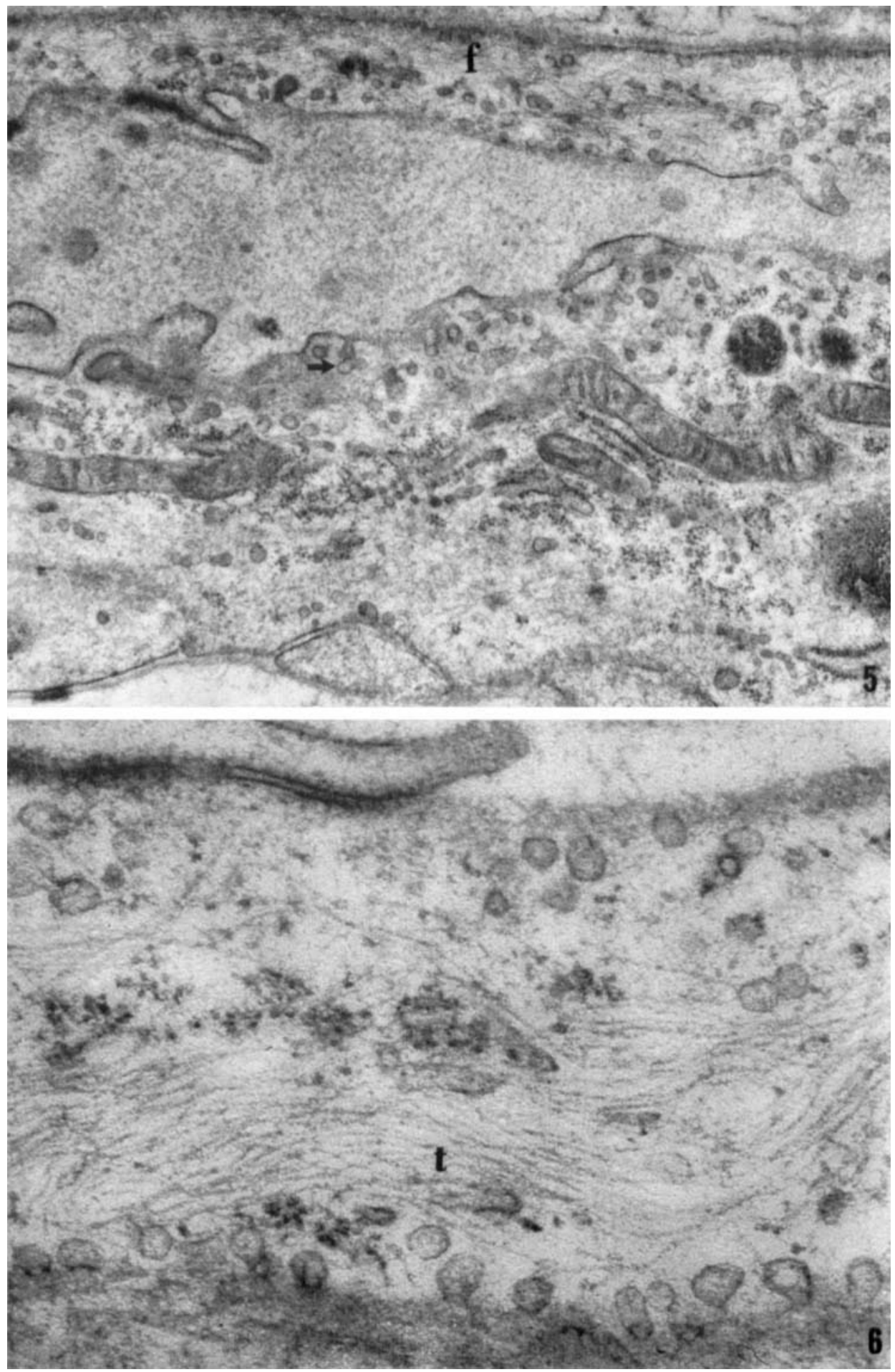
PLATE 4

EXPLANATION OF FIGURES

7 A portion of the luminal surface of an endothelial cell, showing a flap-like protrusion of the cytoplasm. $\times 32,000$.

8- 10 Illustrate attenuated peripheral portions of the cytoplasm of endothelial cells. Inpocketings of the basal plasma membrane (fig. 8) might produce transitory pores in extremely thin part of cytoplasm (fig. 9), and coalescence of such inpocketings and vesicles might result in the formation of a transient channel (fig. 10). Figures 8 and $9, \times 84,000$. Figure $10, \times 98,000$.

Figs. 11 to 14 Intercellular junctions between endothelial cells.

11 Cytoplasmic flaps (arrows) are seen at the two intercellular junctions. A large invagination of the luminal plasma membrane is present at the base of the flap on the left. $\times 18,000$.

12 Simple contact relationship between the cells is evident. Both cytoplasmic ends have small protrusions sticking out into the lumen of the vessel. $\times 23,200$.

13 The protrusions appear to be larger than the ones in figure 12. That they are compressed by the red blood cell $(\mathrm{r})$ is suggested by the wrinkled appearance of the membrane. $\times 28,600$.

14 At least four cytoplasmic ends (a to d) participate in making up this rather complicated junction. $\times 28,600$. 

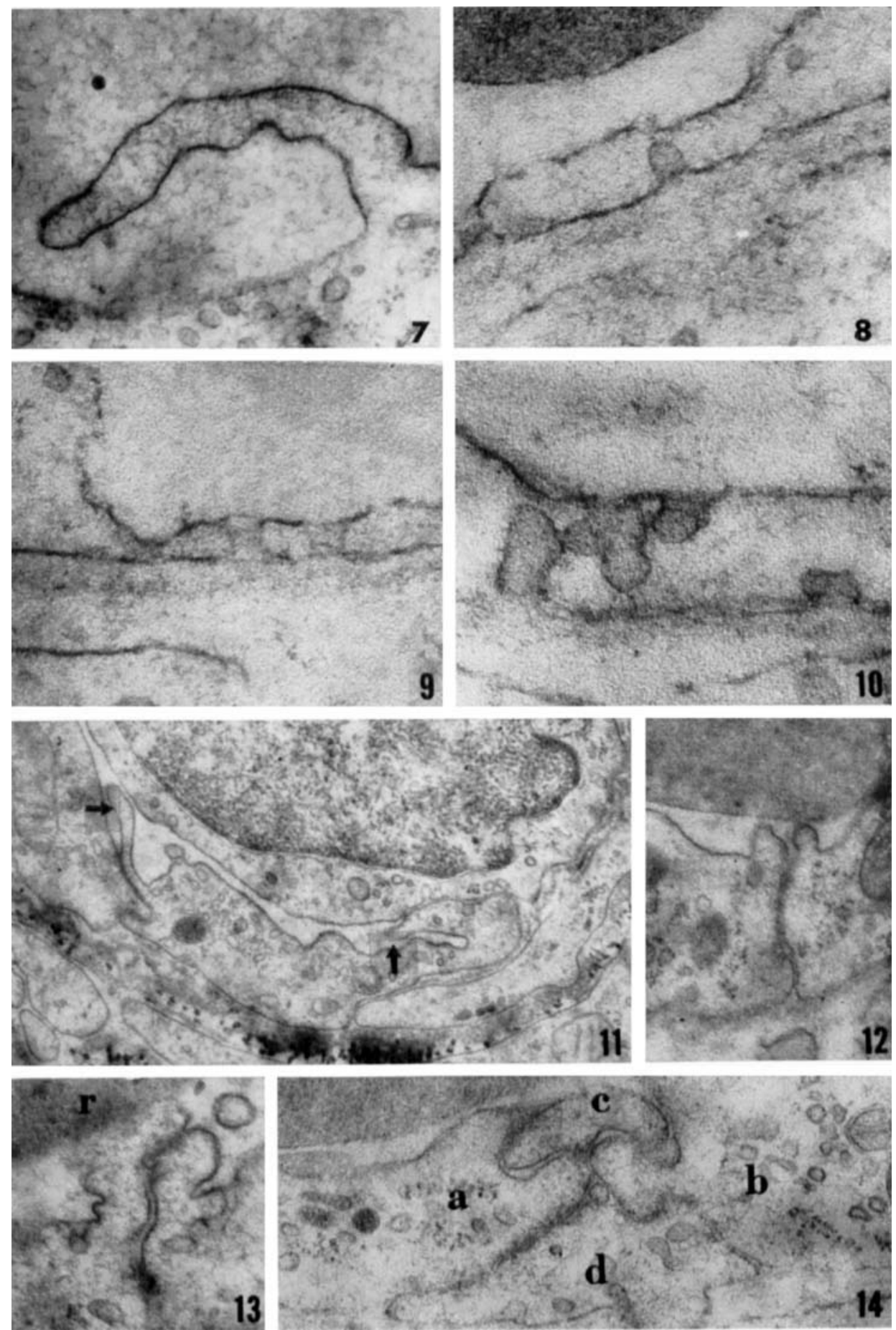
Plate 5

EXPLANATION OF FIGURES

Figs. 15 to 20 Intercellular junctions of the endothelium.

15 Only one cytoplasmic end contributes a flap, which is bent over to cover the adjacent cell. An invagination of the surface membrane is present at the base of the flap. $\times 24,000$.

16 A remarkable uniformity in the width of the intercellular space is demonstrated in this long, interdigitating junction. $\times 32,000$.

17 Another interdigitation showing a few attachment zones (arrows), and a third cytoplasmic process under it. $\times 41,200$.

18 An intermediate type between overlapping and interdigitation. Another flap appears to cover the junction from a third direction. $\times 27,200$.

19 Plasma membranes along the intercellular space show two inpocketings which are located between attachment zones (arrows). $\times 33,800$.

20 An intermediate type between overlapping and interdigitation similar to the one in figure 18. The invagination (arrow) at the base of the flap is apparent. $\times 22,600$. 

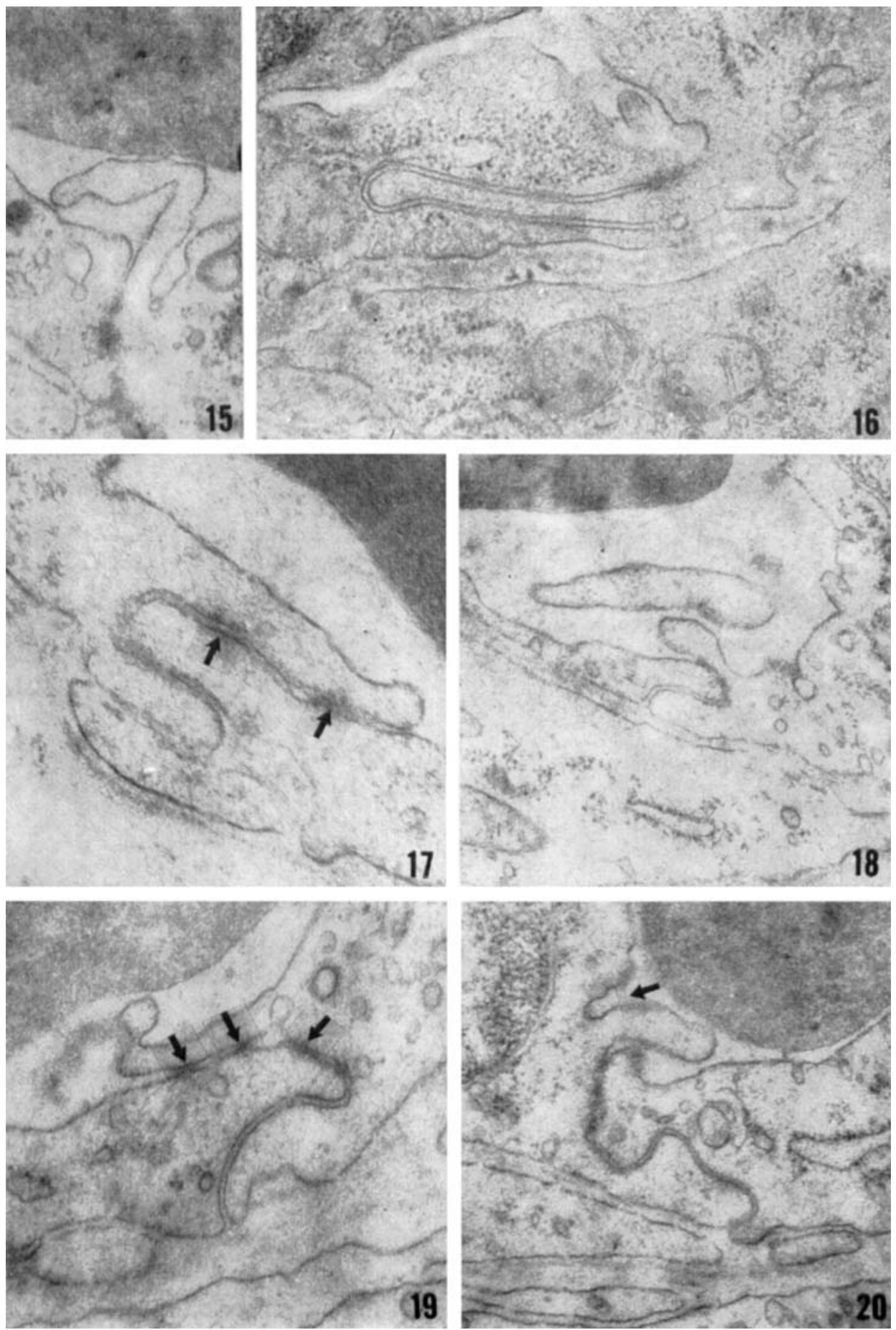
PLATE 6

EXPLANATION OF FIGURES

21 An intercellular junction with numerous vesicles ( $v$ ) which appear to form large vacuoles ( $V$ ) by coalescence. Large invaginations of the surface membrane are also present (arrows). $\times 33,200$.

22 An intercellular junction with attachment zones (arrows) and dilatations (d) of the intercellular space. No dilatations of the space are seen at attachment zones. $\times 33,800$. 

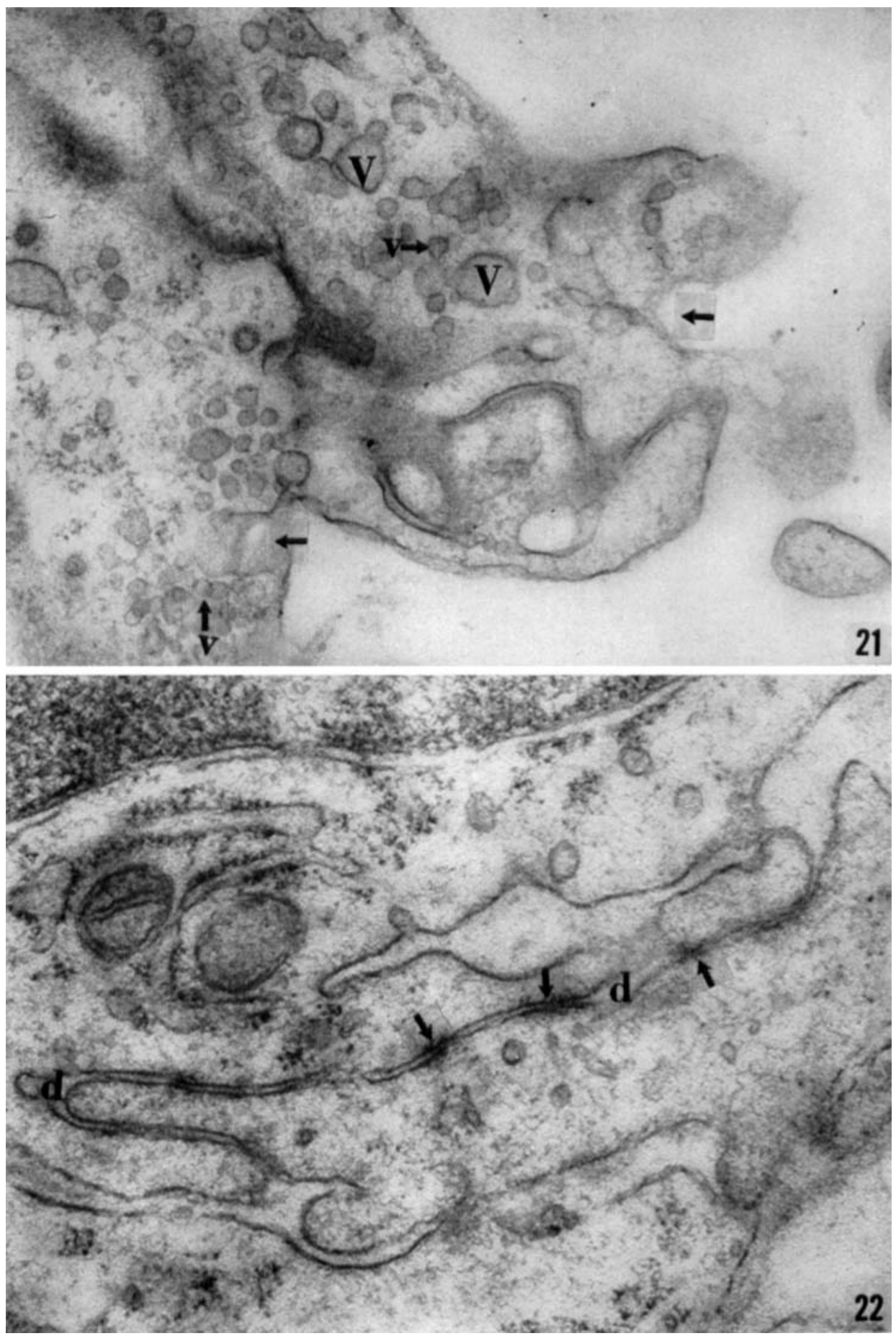
PLATE 7

EXPLANATION OF FIGURES

23 A transverse section of a small capillary. The surface membrane facing the lumen shows a highly irregular appearance. The shape of the flaps (f) suggests that, by merging with the portions of the surface membrane closest to their tips, they could produce large vacuoles similar to those present elsewhere (arrows). A number of collagen fibrils are noticed along the outer border of basement membrane. A portion of the pericyte ( $p$ ) as well as a few unmyelinated nerve fibers $(n)$ can be seen on the right. $\times 22,000$.

24 A portion of the cytoplasm of a pericyte. Many profiles of rough endoplasmic reticulum and a prominent Golgi complex (G) closely resemble the cytoplasm of fibroblasts. Two dense bodies are seen within the vicinity of the Golgi complex. A small portion of the capillary endothelium is seen at the lower right corner. $\times 26,800$. 


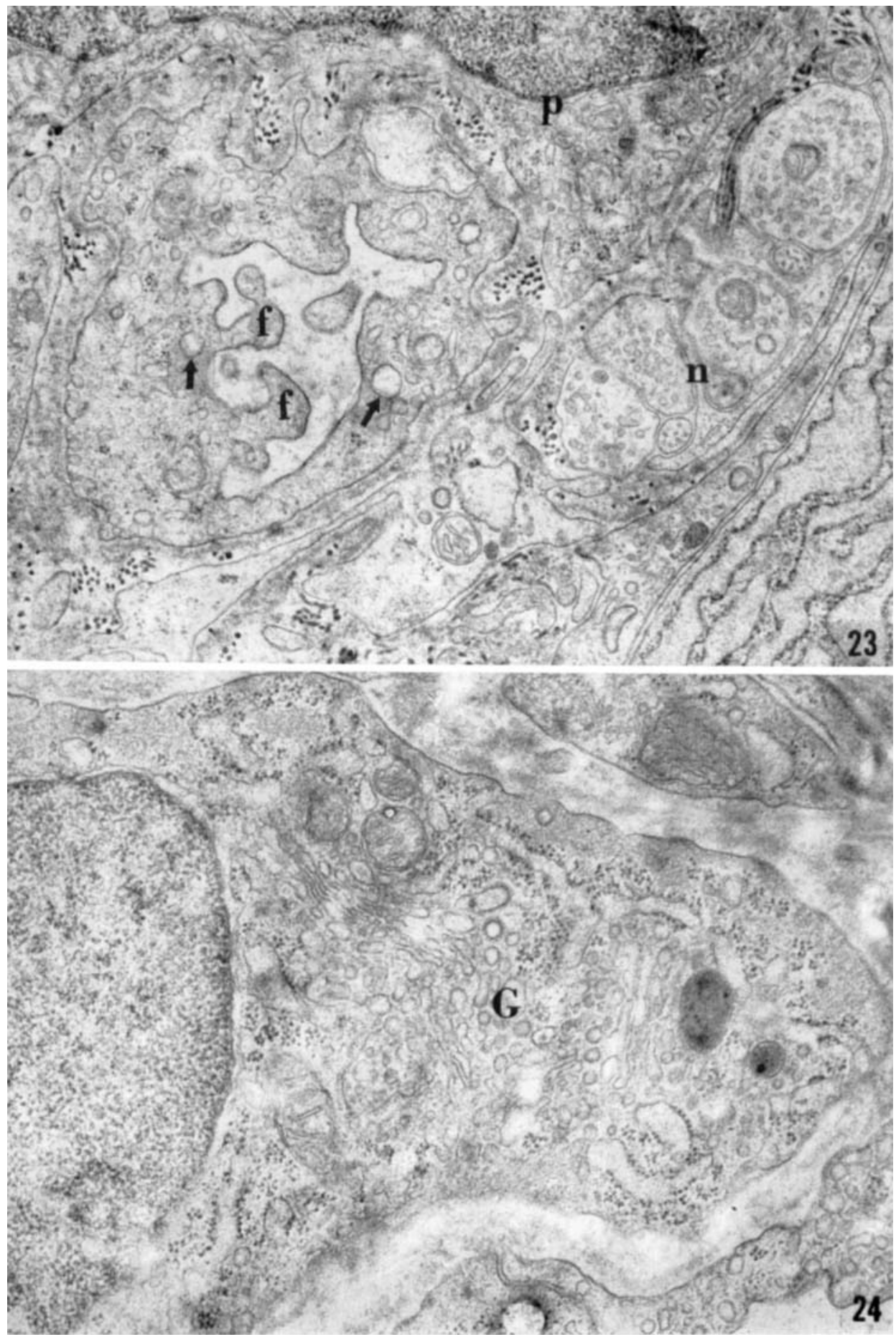




\section{PLATE 8}

EXPLANATION OF FIGURES

25 Portions of smooth muscle cells in the media of a small artery, sectioned transversely relative to the direction of myofibrils which fill up the cytoplasm except the central region where most cytoplasmic organelles are aggregated. Attachment zones are produced by plasma membranes closely brought together (arrows). The rest of the intercellular region contains a large number of collagen fibrils ( $f$ ). Small vesicles and inpocketings are seen along the plasma membrane. $\times 17,400$.

26 A portion of the boundary between the media (right) and adventitia (left) of a small artery. The smooth muscle cell is longitudinally cut, and myofibrils make up several fusiform densities (d) in certain regions. Under the plasma membrane are many small vesicles $(v)$. Adventitial connective tissue fibers consist of typical collagen fibrils (c), elastic fibers (e) and fine fibrils (f) which are closely associated to the smooth muscle cell as well as to other fibrils in the region. $\times 42,600$. 

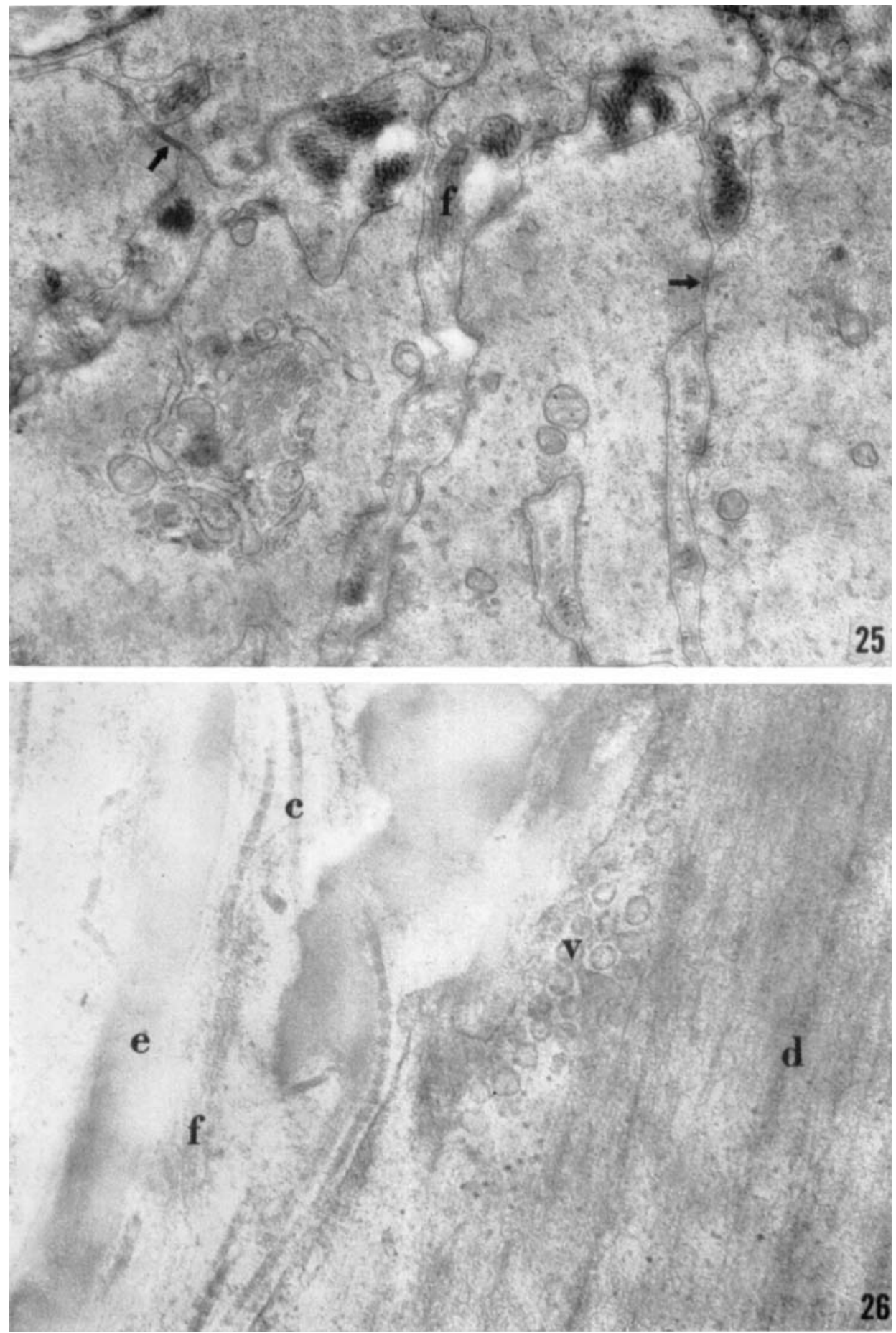